EGU2020-5369, updated on 14 Jan 2021

https://doi.org/10.5194/egusphere-egu2020-5369

EGU General Assembly 2020

(c) Author(s) 2021. This work is distributed under

the Creative Commons Attribution 4.0 License.

\title{
The FOCUS experiment 2020 (Fiber Optic Cable Use for Seafloor studies of earthquake hazard and deformation)
}

\author{
Marc-Andre Gutscher ${ }^{1}$, Jean-Yves Royer ${ }^{1}$, David Graindorge ${ }^{1,2}$, Shane Murphy ${ }^{3}$, Frauke \\ Klingelhoefer ${ }^{3}$, Chastity Aiken ${ }^{3}$, Antonio Cattaneo ${ }^{3}$, Giovanni Barreca ${ }^{4}$, Lionel Quetel ${ }^{5}$, Giorgio \\ Riccobene $^{6}$, Salvatore Aurnia ${ }^{1,6}$, Florian Petersen ${ }^{7}$, Dietrich Lange ${ }^{7}$, Morelia Urlaub ${ }^{7}$, Seabstian \\ Krastel $^{8}$, Felix Gross ${ }^{8}$, Heidrun Kopp ${ }^{7}$, Milena Moretti ${ }^{9}$, Laura Beranzoli ${ }^{9}$, Nadia Lo Bue ${ }^{9}$, and the \\ FOCUS Team* \\ ${ }^{1}$ CNRS UMR6538, Laboratoire Géosciences Océan, Plouzane, France (gutscher@univ-brest.fr) \\ ${ }^{2}$ Univ. Brest UMR6538, Laboratoire Géosciences Océan, Plouzane, France (gutscher@univ-brest.fr) \\ ${ }^{3}$ Unité Géosciences Marines, Ifremer Centre Atlantique, Plouzane, France \\ ${ }^{4}$ Dept. of Biological, Geological and Environmental Science, Univ. Catania, Italy \\ ${ }^{5}$ IDIL Fiber Optics, Lannion, France \\ ${ }^{6}$ INFN-LNS, Catania, Italy \\ ${ }^{7}$ Helmholtz Centre for Ocean Research, Geomar, Kiel, Germany \\ ${ }^{8}$ Institute of Geosciences, Univ. Kiel, Kiel, Germany \\ ${ }^{9}$ INGV, Rome, Italy \\ ${ }^{*}$ A full list of authors appears at the end of the abstract
}

Laser reflectometry (BOTDR), commonly used for structural health monitoring (bridges, dams, etc.), for the first time is being tested to study movements of an active fault on the seafloor, $25 \mathrm{~km}$ offshore Catania Sicily (an urban area of 1 million people). Under ideal conditions, this technique can measure small strains (10E-6), across very large distances $(10-200 \mathrm{~km})$ and locate these strains with a spatial resolution of $10-50 \mathrm{~m}$. As the first experiment of the European funded FOCUS project (ERC Advanced Grant), in late April 2020 we aimed to connect and deploy a dedicated 6-km long strain cable to the TSS (Test Site South) seafloor observatory in $2100 \mathrm{~m}$ water depth operated by INFN-LNS (Italian National Physics Institute). The work plan for the marine expedition FocusX1 onboard the research vessel PourquoiPas? is described here. First, microbathymetric mapping and a video camera survey are performed by the ROV Victor 6000 . Then, several intermediate junction frames and short connector cables (umbilicals) are connected. A cable-end module and 6-km long fiber-optic strain cable (manufactured by Nexans Norway) is then connected to the new junction box. Next, we use a deep-water cable-laying system with an integrated plow (updated Deep Sea Net design Ifremer, Toulon) to bury the cable $20 \mathrm{~cm}$ in the soft sediments in order to increase coupling between the cable and the seafloor. The targeted track for the cable crosses the North Alfeo Fault at three locations. Laser reflectometry measurements began April 2020 and will be calibrated by a three-year deployment of seafloor geodetic instruments (Canopus acoustic beacons manufactured by iXblue) also started April 2020, to quantify relative displacement across the fault. During a future marine expedition, tentatively 
scheduled for 2021 (FocusX2) a passive seismological experiment is planned to record regional seismicity. This will involve deployment of a temporary network of OBS (Ocean Bottom Seismometers) on the seafloor and seismic stations on land, supplemented by INGV permanent land stations. The simultaneous use of laser reflectometry, seafloor geodetic stations as well as seismological land and sea stations will provide an integrated system for monitoring a wide range of types of slipping events along the North Alfeo Fault (e.g. - creep, slow-slip, rupture). A long-term goal is the development of dual-use telecom cables with industry partners.

FOCUS Team: all names above, and also Sara Pulvirenti (INFN-LNS Catania, Italy), Viorel Ciausu (Ifremer Centre Méditerranée, Toulon, France), Philippe Jousset (GFZ Potsdam, Germany) 